\title{
Accelerated lifetime testing of energy storage capacitors used in particle accelerators power converters
}

Fulvio Boattini; Charles-Mathieu Genton

CERN, Geneva, Switzerland,

Keywords: «Storage Capacitors», «Ageing», «Power converters», «metalized film»

\begin{abstract}
Energy storage capacitors are used in large quantities in high power converters for particle accelerators. In this application capacitors see neither a DC nor an AC voltage but a combination of the two. The paper presents a new power converter explicitly designed to perform accelerated testing on these capacitors and the results of the tests.
\end{abstract}

Presented at: EPE 2015, 7-10 September 2015, Geneva, Switzerland

Geneva, Switzerland

October, 2015 


\title{
Accelerated lifetime testing of energy storage capacitors used in particle accelerators power converters
}

\author{
Fulvio Boattini; Charles-Mathieu Genton \\ CERN, European Organization for Nuclear Research \\ 1211 Geneva 23, Switzerland \\ Tel: +41227678542 \\ fulvio.boattini@,cern.ch, charles-mathieu.genton@,cern.ch \\ http://www.cern.ch
}

\section{Keywords}

«Storage Capacitors», «Ageing», «Power converters», «metalized film»

\begin{abstract}
Energy storage capacitors are used in large quantities in high power converters for particle accelerators. In this application capacitors see neither a DC nor an AC voltage but a combination of the two. The paper presents a new power converter explicitly designed to perform accelerated testing on these capacitors and the results of the tests.
\end{abstract}

\section{Introduction}

At CERN several power converters are used to supply current to magnets in particle accelerators. The typical load cycle is represented by a current pulse starting from a low value where particles are injected and rising up as they are accelerated. After particles are ejected at the flat top, the current is brought back to zero and another cycle is started.
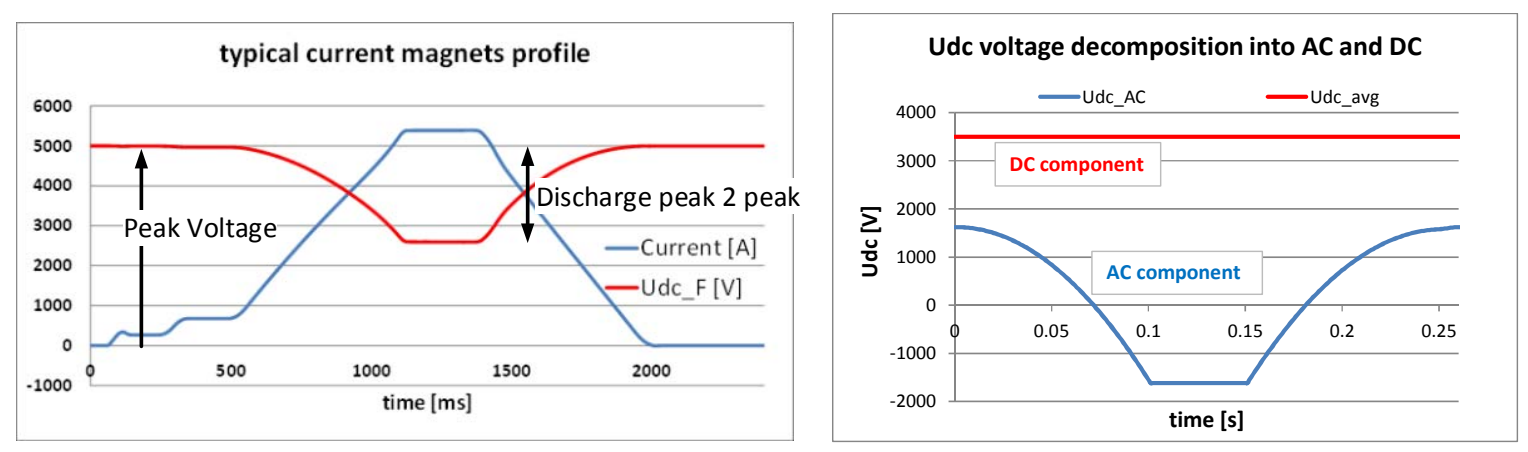

Figure 1. Typical magnets current cycle and storage capacitor voltage shape

Given the inductive nature of the load, the mean power is in general much lower than the peak. This is particularly important for multi megawatt power converters where power swings of several tens of MW are requested to the $\mathrm{AC}$ network as a consequence of the huge peak power of the magnets. Capacitor energy storage is very effective in limiting these power oscillations. The energy stored by capacitors in electric form is exchanged with the magnetic energy of the magnets such that when the magnets current increases, the capacitors voltage decreases (Figure 1).

In its application as energy storage elements, capacitors undergo atypical voltage conditions with a combination of $\mathrm{AC}$ at low frequency and DC components; a load condition not deeply investigated by capacitor producers.

Given the considerable quantity of energy storage capacitors installed in present and future projects, CERN decided to build a testing laboratory for assessing the lifetime of the solutions proposed by different companies. 


\section{Storage capacitors technology}

All tested solutions are derived from DC filtering applications with metalized polypropylene film capacitors (MPPFC). The capacitors are realized by a parallel-series connection of many basic units each formed by hundreds of meters of polypropylene metalized film tightly superimposed to each other (Figure 2). The polypropylene film for this range of application is typically 4 to $12 \mathrm{um}$ thick; a layer (20 to $200 \mathrm{~nm}$ ) of $\mathrm{Al}, \mathrm{Al}+\mathrm{Zn}, \mathrm{Zn}$ metallization is vacuum deposited on the film surface, forming the capacitor electrodes. MPPFC are available either oil impregnated or not oil impregnated (some manufacturers use oil not for film impregnation but as a filler). When impregnated the PP film increases the breakdown electric field from the theoretical maximum of $640 \mathrm{~V} / \mathrm{pm}$ to $810 \mathrm{~V} / \mathrm{pm}$ (e.g. $25 \%$ ) [3]; the basic units shall therefore be less hard wounded to allow the impregnating oil to penetrate among the different film layers (Figure 2 right; rough type PP film are used in this case). Typically vegetable oils (rapeseed, castor...) are used for polypropylene impregnated capacitors. Nonimpregnated capacitors, on the other hand, are tightly wounded in a solid rock unit (Figure 2 left); the higher the pressure, the lower is the amount of energy required for the self-healing to operate [2][4] and therefore the smallest is the impact of clearing defects.

The robustness of MPPFC resides in a characteristics property called self-healing defined as the capacity to gracefully eliminate short circuits among electrodes by a controlled vaporization of the electrodes around the default. Many papers [1], [2], [5] propose the discharge energy as the main parameter characterizing the self-healing in MPPFC:

[1] $E_{\text {discharge }}=\frac{k \cdot V^{4.7} \cdot C}{(o h m / s q)^{1.8} \cdot \alpha(P)}$

$\mathrm{V}=$ voltage applied; ohm/sq=surface resistivity of the metallization; $\alpha(\mathrm{P})=$ function of the interlayer pressure.

Equation (1) is very useful to understand the main parameters influencing the self-healing efficiency to avoid dramatic failure of the capacitors. The smaller the discharge energy the easier it is to stop any breakdown initiated by unavoidable defects present in the capacitor and therefore to have an efficient self-healing mechanism.
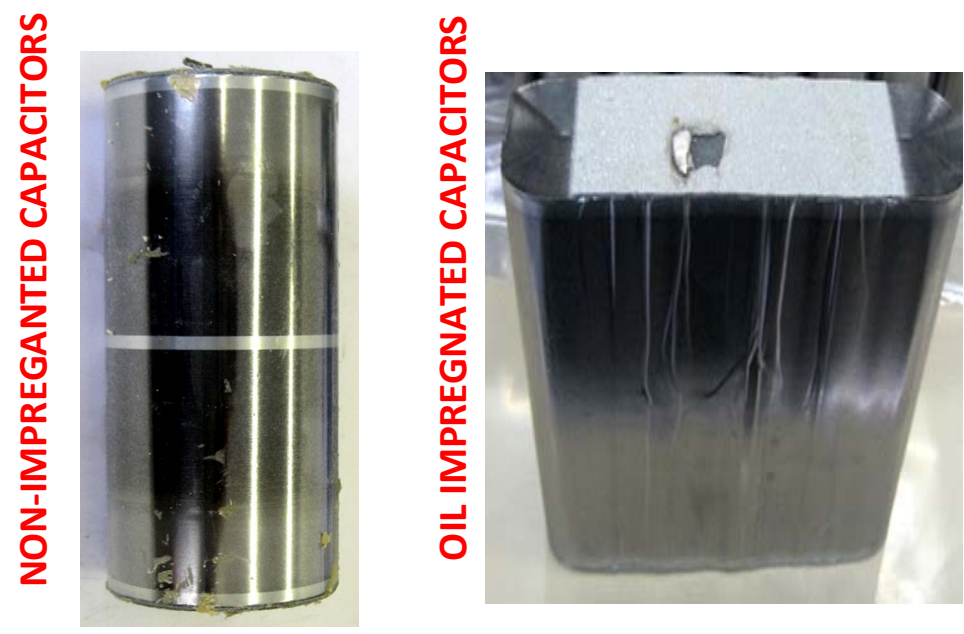

Figure 2. Basic unit shape for non-impregnated (left) and oil impregnated (right) capacitors.

The electric field through the polypropylene dielectric film has a fundamental importance in the design of capacitors. Not only must it be lower than the polypropylene breakdown value, but it must limit the discharge energy in the self-healing process. To reduce the electric field in the PP film to an admissible value, different suppliers propose either external series of various basic units, or internal series realized by an appropriate electrode-film pattern as showed in Figure 3. 

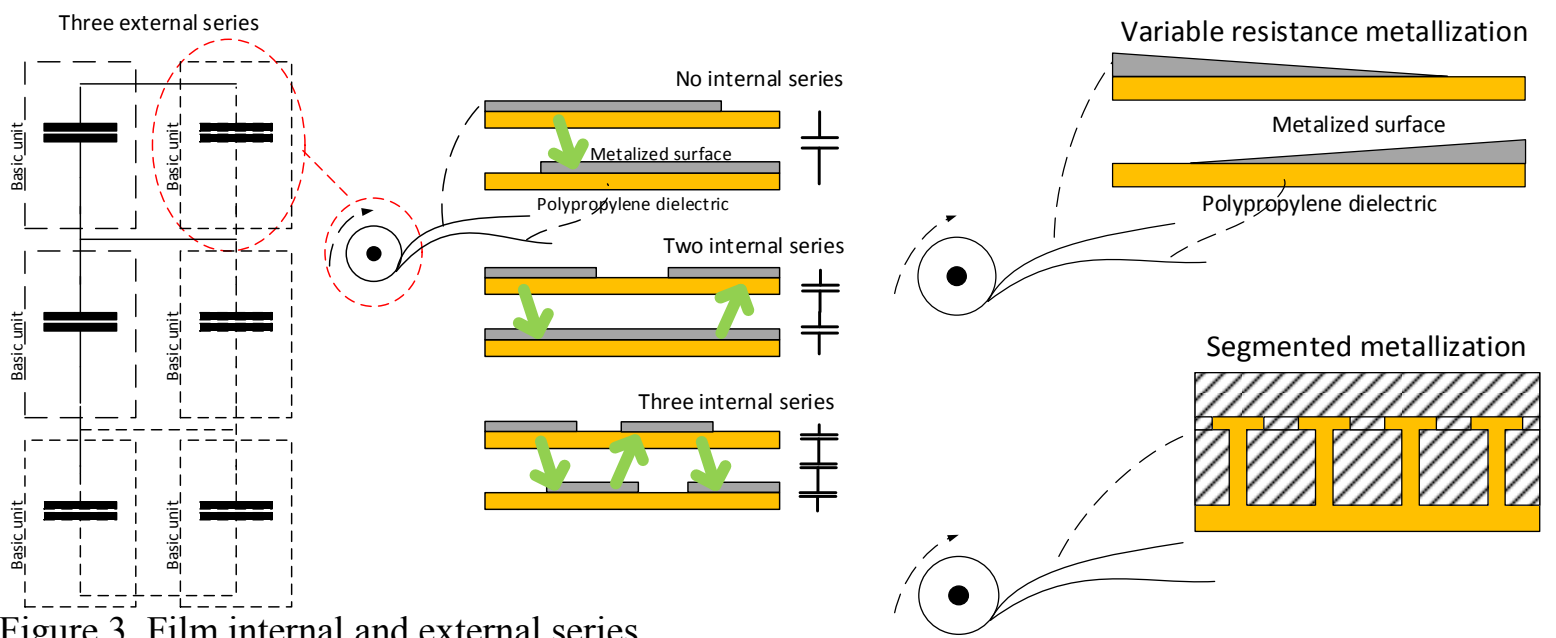

Figure 3. Film internal and external series

Figure 4. Different approaches to MPPFC metallization: variable thickness (left) and segmented (right).

From (1) we can understand the interest of increasing metallization resistivity in order to have high electric field (and thus energy density) and still possess an efficient self-healing mechanism.

The drawback of increasing metallization resistivity is that a thin metallization is required that is more prone to electrochemical corrosion. This is the second most important ageing mechanism of MPPFC that appears as a progressive loss of the metallization leading to marked capacitance loss.

To solve this issue, capacitor producers employ different metallizing alloys the most used being $\mathrm{Al}+\mathrm{Zn}$. The addition of $\mathrm{Zn}$ greatly reduces the electro corrosion effect on thin metallization layers. Alternatively a segmented or variable resistance metallization can be used (Figure 4).

\section{A power converter for testing capacitors}

A special power converter has been designed and produced for the capacitors accelerated testing laboratory. The main characteristic the power converter shall possess is the ability to generate voltage waveforms with an arbitrary shaped AC component offset by a DC value as shown in Figure 1.

The power converter schematic principle is highlighted in Figure 5. A DC source is connected in series with two AC sources in order to generate the desired voltage waveform across the capacitors under test (Cdut).

The DC source consists of a step-up transformer connected to a 12-pulse diode rectifier. The output voltage can be regulated with a variac from 0 to $6200 \mathrm{~V}$. A parallel capacitor bank (Cbyp) is required to allow the $\mathrm{AC}$ current to circulate. This capacitance is in series with the one under test and must therefore be much bigger so that the $\mathrm{AC}$ voltage generated by the $\mathrm{AC}$ source is taken primarily by the capacitors under test. In order to simplify the design of the AC source, the total voltage is realized by using two single phase inverters with a $1000 \mathrm{~V}$ dc link. The maximum AC voltage that can be generated by the two AC sources is therefore slightly lower than $\pm 4 \mathrm{kV}$. The AC source is virtually capable to generate any desired voltage shape unless the derived peak current is limited to $150 \mathrm{~A} \mathrm{rms}$ and $200 \mathrm{~A} \mathrm{pk}$. Figure 8 shows the power converter in operation and the thermal chamber used for heating up capacitors. The system is capable to either test 4 reduced scale samples at a time or one fully scaled unit.

\section{Control}

The reference for the AC voltage is implemented in a Digital Signal Processor (DSP) from a fixed-size array of values. In order to generate the same reference at different frequencies, an interpolation is used based on a counter $\mathrm{k}$ whose length is frequency dependent.

$V_{\text {ref }}=\left(\right.$ Array $_{\frac{k}{D T}+1}-$ Array $\left._{\frac{k}{D T}}\right) *\left(k-\operatorname{int}\left(\frac{k}{D T}\right) * D T\right)+$ Array $_{\frac{k}{D T}}$

Where DT marks the number of increments between two consecutive array cells. 


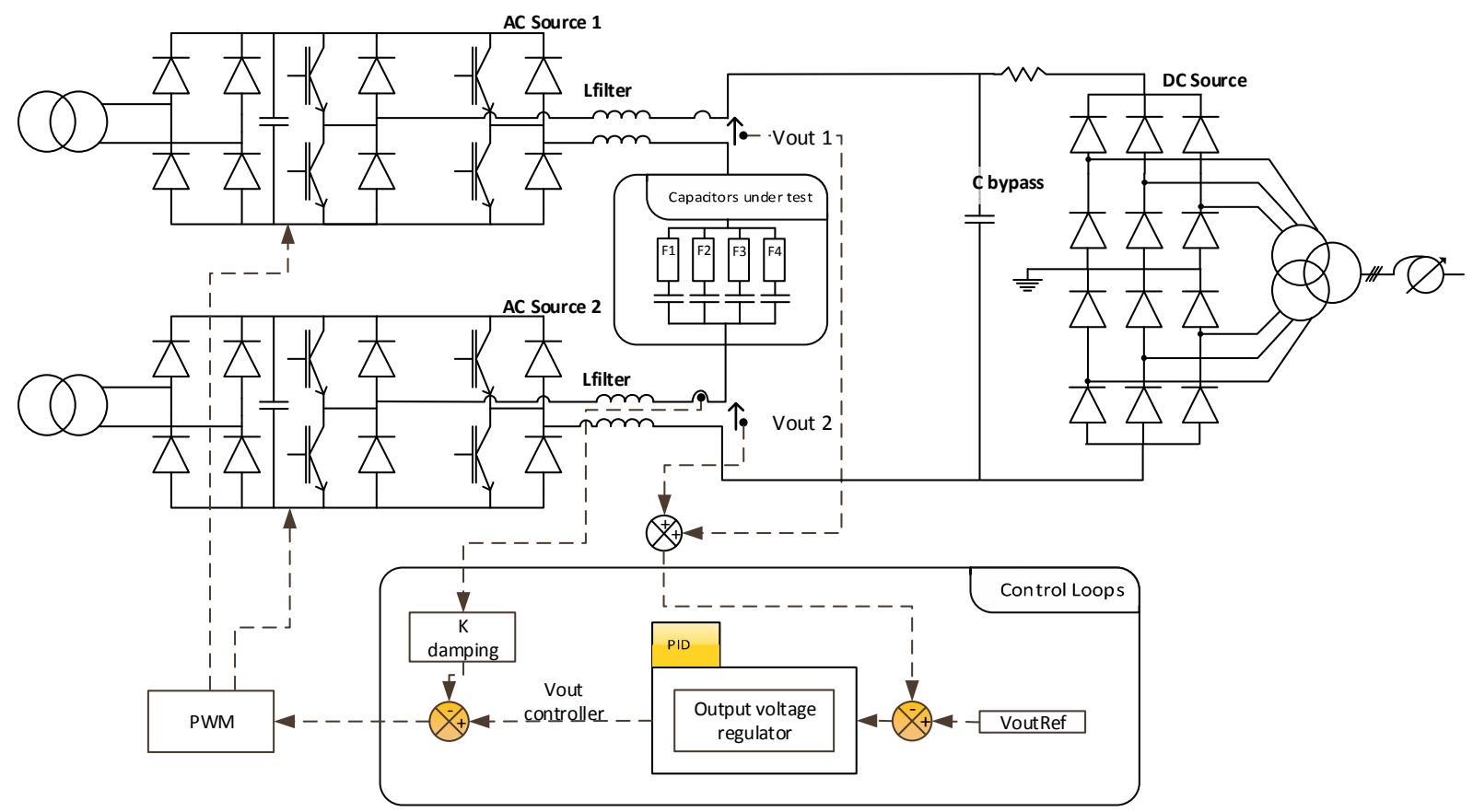

Figure 5: Simplified schematic of the Capacitor testing power converter

The capacitors under test and the filter inductors create an un-damped LC circuit resonating at different frequencies depending upon the value of the tested capacitor. The output voltage (AC component only) and currents are shown in Figure 6.
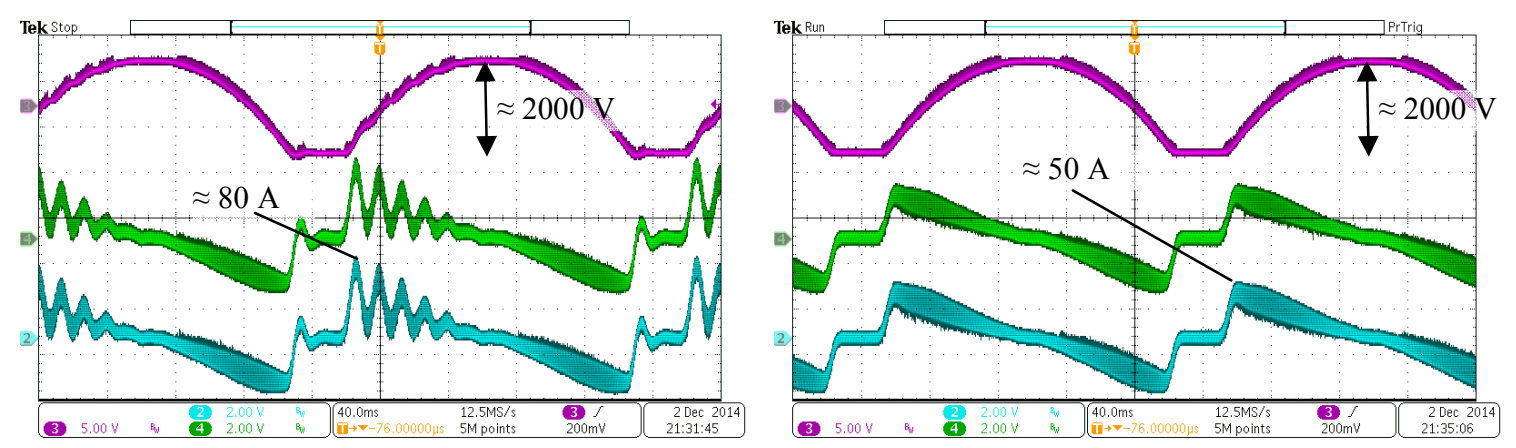

Figure 6: Measured output voltage and currents without (left) and with (right) damping

The circuit is actively damped by the controller using the measured capacitor current as state feedback in the output of the voltage control regulation loop (Figure 7).

$$
\begin{gathered}
\frac{\operatorname{Vdcut}(s)}{\operatorname{Vout}(s)}=\frac{1}{1+2 \xi \omega_{0} s+\frac{s^{2}}{\omega_{0}^{2}}} \\
\omega_{0}=\frac{1}{\sqrt{L_{\text {filt }} C_{u t}}} ; \xi=\frac{C_{u t} K_{i c}}{2 \omega_{0}}
\end{gathered}
$$

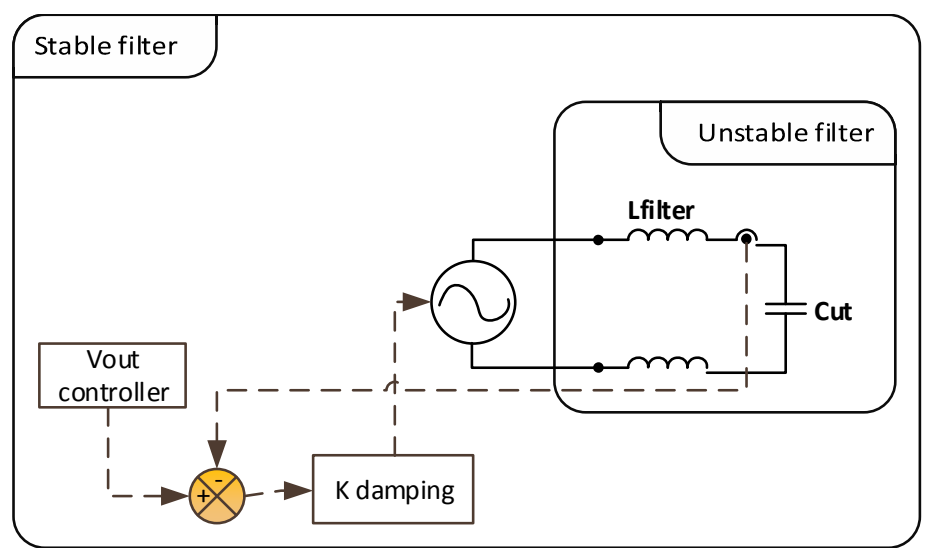

Figure 7: Active damping using the converter output current 


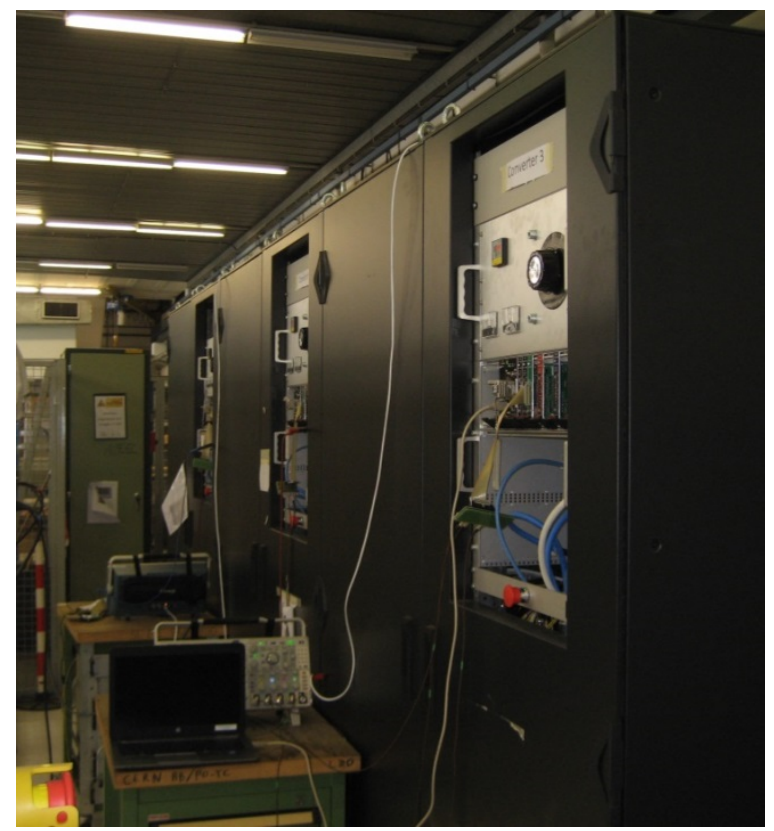

Reduced scale samples

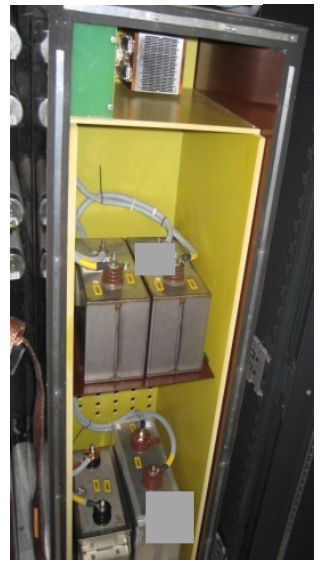

Full scale unit

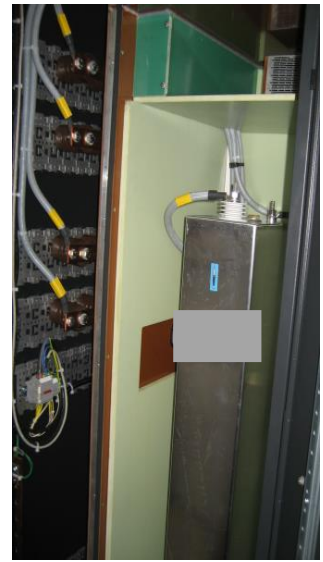

Figure 8: Capacitor testing power converter (left) and heating chamber (left)

The combination of AC and DC components is shown in Figure 9 for the charge-discharge $5 \mathrm{~Hz}$ waveform and for sinusoidal shape.
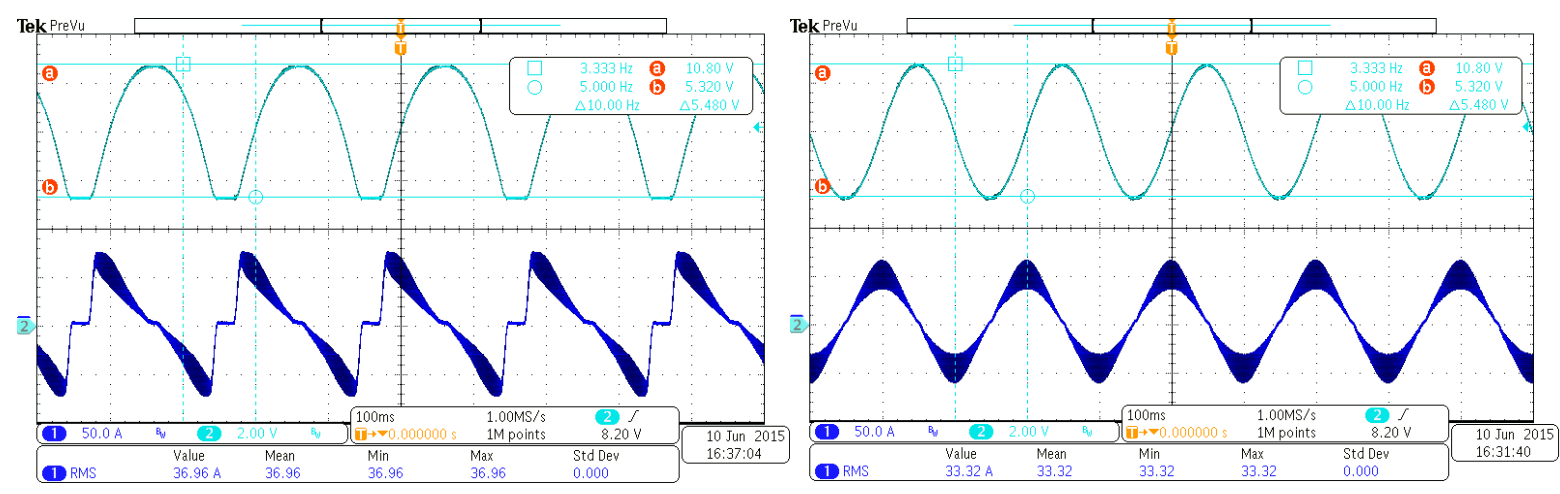

Figure 9: Total voltage applied to the Cdut with a charge-discharge profile at $5 \mathrm{~Hz}$ (left) and with $5 \mathrm{~Hz}$ sinusoidal shape (right)

\section{Accelerated testing criteria}

In the search of the best technology six different solutions from different suppliers were tested. Three of them are non-impregnated capacitors and the remaining are oil-impregnated capacitors.

Besides the filling material, the seven solutions differ in the following main characteristics:

- Internal and external number of series;

- Metallization material and pattern.

For the accelerated testing the end of life criteria is defined as a loss of 5\% in capacitance value. To accelerate the ageing, we played on the following accelerating factors:

- Testing ambient temperature;

- Peak voltage applied to the capacitors (Figure 1);

- Discharge repetition rate.

A simplified model for lifetime evaluation of MPPFC is very often proposed as below [5]:

$$
\mathrm{L}_{\mathrm{acc}}=\mathrm{L}_{0} \cdot \mathrm{e}^{\mathrm{B} \cdot\left(\frac{1}{\mathrm{~T}_{\mathrm{acc}}}-\frac{1}{\mathrm{~T}_{0}}\right)} \cdot\left(\frac{\mathrm{V}_{0}}{\mathrm{~V}_{\mathrm{acc}}}\right)^{\mathrm{C}}
$$




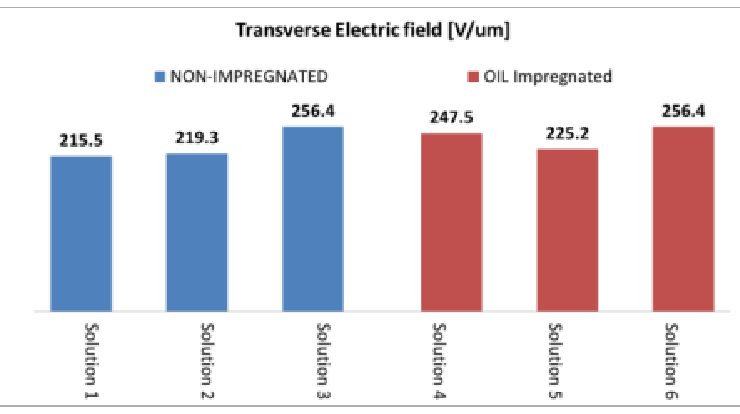

Figure 10: Analyzed solutions transverse electric field and energy density
Table 1: Analyzed solutions film layout description

\begin{tabular}{|l|l|}
\hline Solution 1 & $\begin{array}{l}\text { Non-impregnated. Two internal + Two } \\
\text { external series. Variable resistance } \\
\text { metallization Al+Zn }\end{array}$ \\
\hline Solution 2 & $\begin{array}{l}\text { Non-impregnated. Segmented metallization } \\
\text { with Al+Zn. Two internal series. }\end{array}$ \\
\hline Solution 3 & $\begin{array}{l}\text { Non-impregnated. Three internal series. } \\
\text { Al+Zn metallization. }\end{array}$ \\
\hline Solution 4 & $\begin{array}{l}\text { Oil-impregnated. Al metallization. Two } \\
\text { capacitor Internal series }\end{array}$ \\
\hline Solution 5 & $\begin{array}{l}\text { Oil-impregnated. Al metallization. Three } \\
\text { internal series. }\end{array}$ \\
\hline Solution 6 & $\begin{array}{l}\text { Oil-impregnated. Al metallization. No } \\
\text { internal series. Three external series. }\end{array}$ \\
\hline
\end{tabular}

The dependency upon temperature is often simplified by stating that for each increase of $10^{\circ} \mathrm{C}$ of the hot-spot temperature inside capacitors the lifetime is reduced by $50 \%$. Equation (4) shows a power dependency upon the peak voltage applied; the authors attempted a value of eight [2] for this coefficient. In addition, considering a linear relation with the repetition frequency, we can derive an estimation of the accelerated testing time required to evaluate the lifetime of capacitors in operating conditions (Table 2).

Table 2: Preliminary calculation of testing time

\begin{tabular}{|l|l|}
\hline Required lifetime $(5500 \mathrm{~h} /$ years $x$ 20 years $)[\mathrm{h}]$ & 110000 \\
\hline Repetition frequency $[\mathrm{Hz}]$ & 5 \\
\hline B coefficient & 168 \\
\hline C coefficient & 8 \\
\hline Total accelerated testing time $\left(\mathrm{T}_{\mathrm{acc}}=60^{\circ} \mathrm{C} ; \mathrm{To}=40^{\circ} \mathrm{C} ; \mathrm{V}_{\mathrm{acc}}=1.3 \times \mathrm{V}_{0}\right)[\mathrm{h}]$ & $\approx 700$ \\
\hline
\end{tabular}

According to these approximate calculations, a test of $700 \mathrm{~h}$ at $60^{\circ} \mathrm{C}$ with a repetition frequency of 5 $\mathrm{Hz}$ should be enough to assess the lifetime behavior in normal operating conditions.

\section{Accelerated testing results}

The testing system is capable to run 4 capacitors in parallel with three different testing conditions, i.e. 12 capacitors at a time. To investigate the influence of temperature and peak voltage over ageing, the three tests of Table 3 were run for each analyzed solution and for a time of $900 \mathrm{~h}$ each.

Table 3: Tests combination

\begin{tabular}{|l|l|l|l|l|}
\hline & Vpk (kV) & T ambient (C) & Vac pk2pk (kV) & $\mathbf{f}(\mathbf{H z})$ \\
\hline Test 1 & 6.5 & 60 & $\mathbf{3 . 3}$ & $\mathbf{5}$ \\
\hline Test 2 & 5.5 & 60 & $\mathbf{3 . 3}$ & $\mathbf{5}$ \\
\hline Test 3 & 6.5 & 50 & $\mathbf{3 . 3}$ & $\mathbf{5}$ \\
\hline
\end{tabular}

Results are reported in Table 4 and

Figure 11.

Table 4: Capacitance loss during the three tests

\begin{tabular}{|c|c|c|c|c|c|c|c|}
\hline \multicolumn{2}{|c|}{ Design electric field } & \multicolumn{2}{|c|}{ Test $16.5 \mathrm{kV} \mathrm{60}{ }^{\circ} \mathrm{C}$} & \multicolumn{2}{|c|}{ Test $25.5 \mathrm{kV} 60^{\circ} \mathrm{C}$} & \multicolumn{2}{|c|}{ Test $36.5 \mathrm{kV} \mathrm{50}{ }^{\circ} \mathrm{C}$} \\
\hline & {$[\mathbf{V} / \mathbf{u m}]$} & $\mathrm{DC}[\%]$ & Time $[\mathrm{h}]$ & $\mathrm{DC}[\%]$ & Time [h] & $\mathrm{DC}[\%]$ & Time $[\mathrm{h}]$ \\
\hline Solution N1 & 216 & 0 & 900 & 0 & 900 & 0 & 900 \\
\hline Solution N2 & 219 & $-2.25 \%$ & 880 & $-1.13 \%$ & 860 & $-1.15 \%$ & 785 \\
\hline Solution N3 & 256 & $-11.65 \%$ & 900 & $-8.82 \%$ & 570 & $-6.14 \%$ & 880 \\
\hline Solution N4 & 248 & $-9.49 \%$ & 457 & $-10.97 \%$ & 500 & $-17.04 \%$ & 910 \\
\hline Solution N5 & 225 & $-76.08 \%$ & 457 & $-28.92 \%$ & 500 & $-5.68 \%$ & 910 \\
\hline Solution N6 & 256 & $-8.89 \%$ & 880 & $-9.55 \%$ & 860 & $-6.68 \%$ & 910 \\
\hline
\end{tabular}



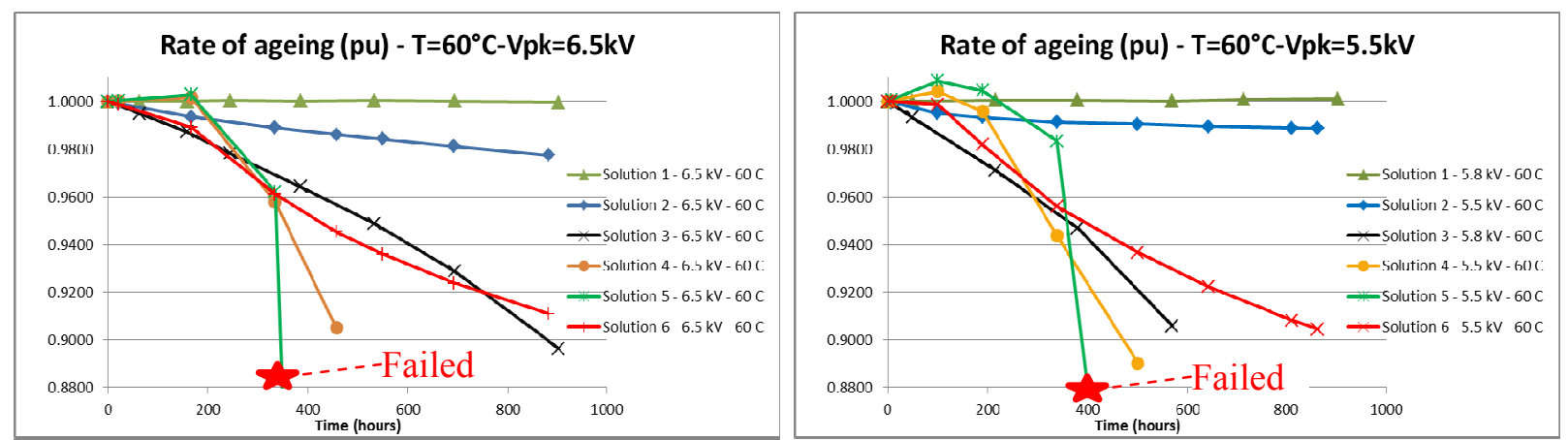

Rate of ageing (pu) $-\mathrm{T}=50^{\circ} \mathrm{C}-\mathrm{Vpk}=6.5 \mathrm{kV}$

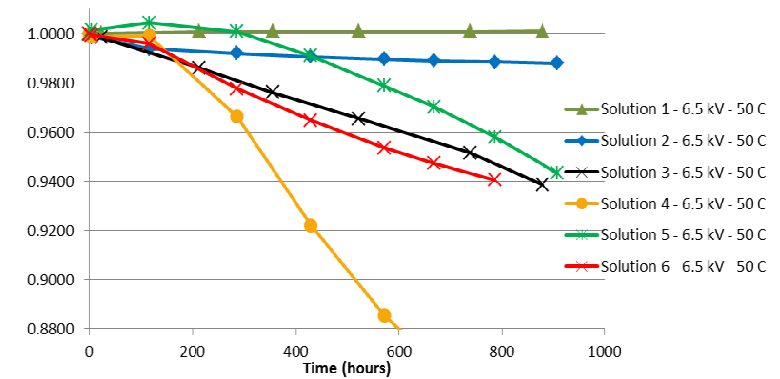

Figure 11: Test 1, Test $2 \&$ Test 3 results comparison

Figure 11 shows the comparison among the different solutions. It appears that solution $\mathrm{N} 1$ and Solution N2 have got the best score in terms of lifetime. This is no surprise as they have the lowest design electric field. When inspecting the film no particular issues have been noticed. Figure 12 shows a self-healing in action where it can be noted the film perforation and fuse blow-up to isolate the interested block of metallization (and lose the relevant amount of capacitance).
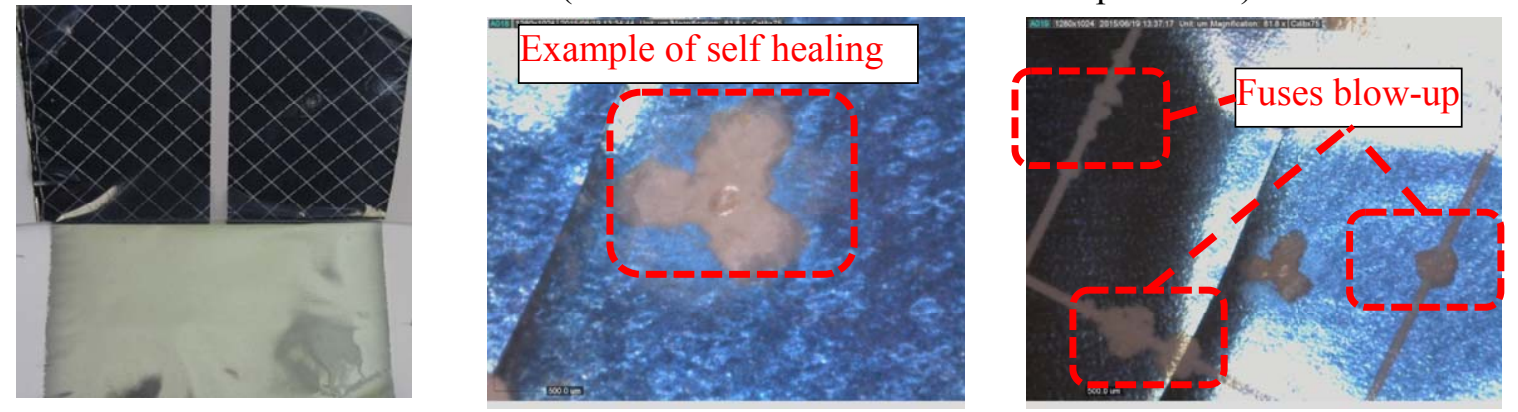

Figure 12: Solution N2 film condition after test1

Using results from Simulation N2 (Figure 13) an attempt has been made to calculate the coefficients of equation (4). Table 5 shows the calculated values. The temperature accelerated coefficient looks much higher than expected giving equivalent much lower accelerated testing time.

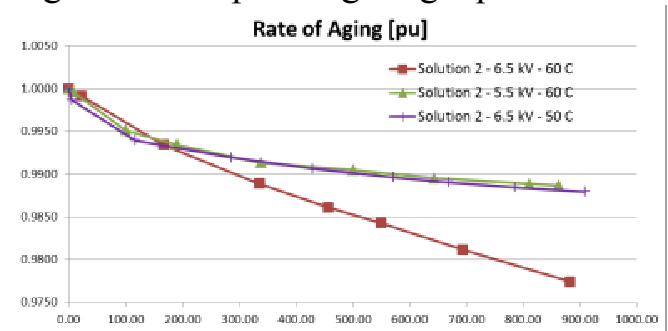

Table 5: Calculation of coefficients for equation (4)

\begin{tabular}{|l|l|}
\hline $\mathrm{B}$ & 346 \\
\hline $\mathrm{C}$ & 8.17 \\
\hline Total accelerated testing time & $\approx 150$ \\
$\left(\mathrm{~T}_{\mathrm{acc}}=60^{\circ} \mathrm{C} ; \mathrm{To}=40^{\circ} \mathrm{C} ; \mathrm{V}_{\mathrm{acc}}=1.3 \times \mathrm{V}_{0}\right)$ & \\
{$[\mathrm{h}]$} & \\
\hline
\end{tabular}

Figure 13: Solution N2 results of the three

tests.

Surprisingly Solution N5 which has the next higher design electric field failed on two out of the three tests. After opening the capacitor (test 1) the internal film showed sign of polypropylene melting 
(Figure 14). The only surviving coil has been unwounded for analysis and it revealed a massive presence of electrode corrosion [2] as manifested by the presence of small circular transparent spots of a radius of $60 \div 180$ um.
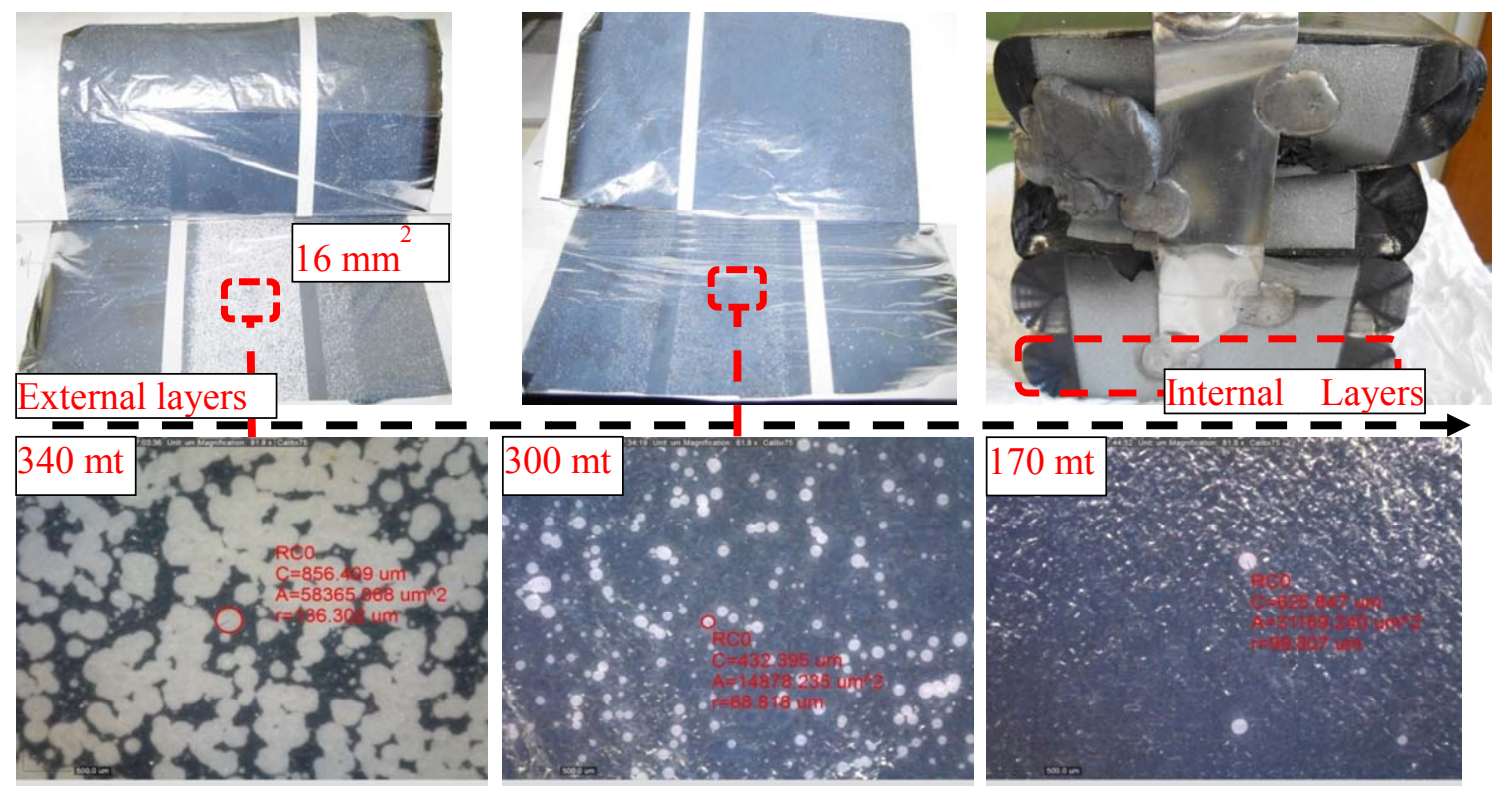

Figure 14: Solution N5 film condition after test1 (350 mt is the total length before starting to unroll)

The corrosion diminishes in the internal layers of the capacitor coil as showed by the microscope pictures reported in Figure 14 at 340, 300 and $170 \mathrm{mt}$ (350 mt is the length of the complete roll, therefore the picture at $340 \mathrm{mt}$ was taken after having unrolled the first $10 \mathrm{mt}$ of film).

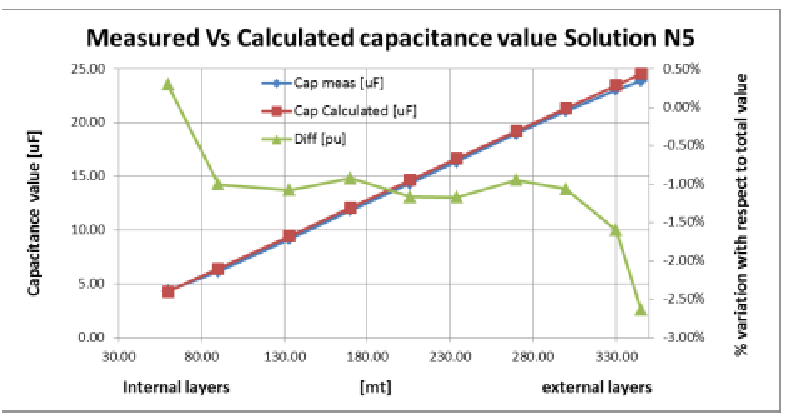

This is confirmed by the measurements of the partial capacitance of the coil as a function of the length of the film showed in Figure 15 where the calculated values are compared to the measured ones (as the winding was unrolled) and the relative loss of capacitance shows to be prominently in the external layers.

Figure 15: Measured Vs Calculated capacitance for Solution N5 single roll.

Similar conclusions can be drawn for Solution N4 where still higher aluminum corrosion has been found although in this case we observed no failures.

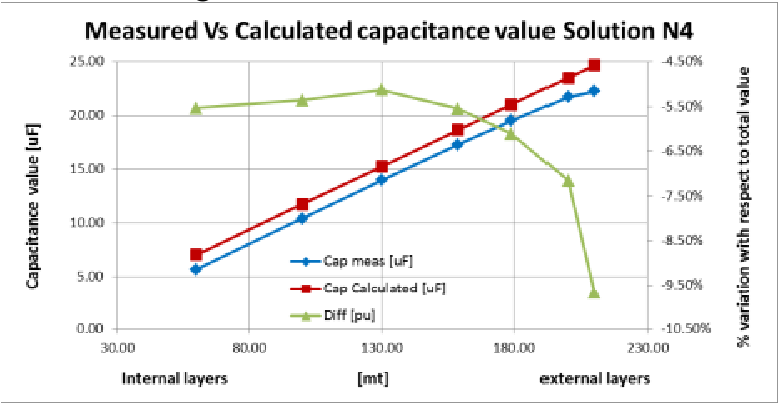

The highest loss of capacitance is still in the external layers, but the corrosion is much more evident due to the highest design electric field of Solution N4. As the internal layers are approached though, corrosion becomes important again and the capacitance drop becomes slightly steeper again (Figure 17).

Figure 16: Measured Vs Calculated capacitance for Solution N4 single roll. 


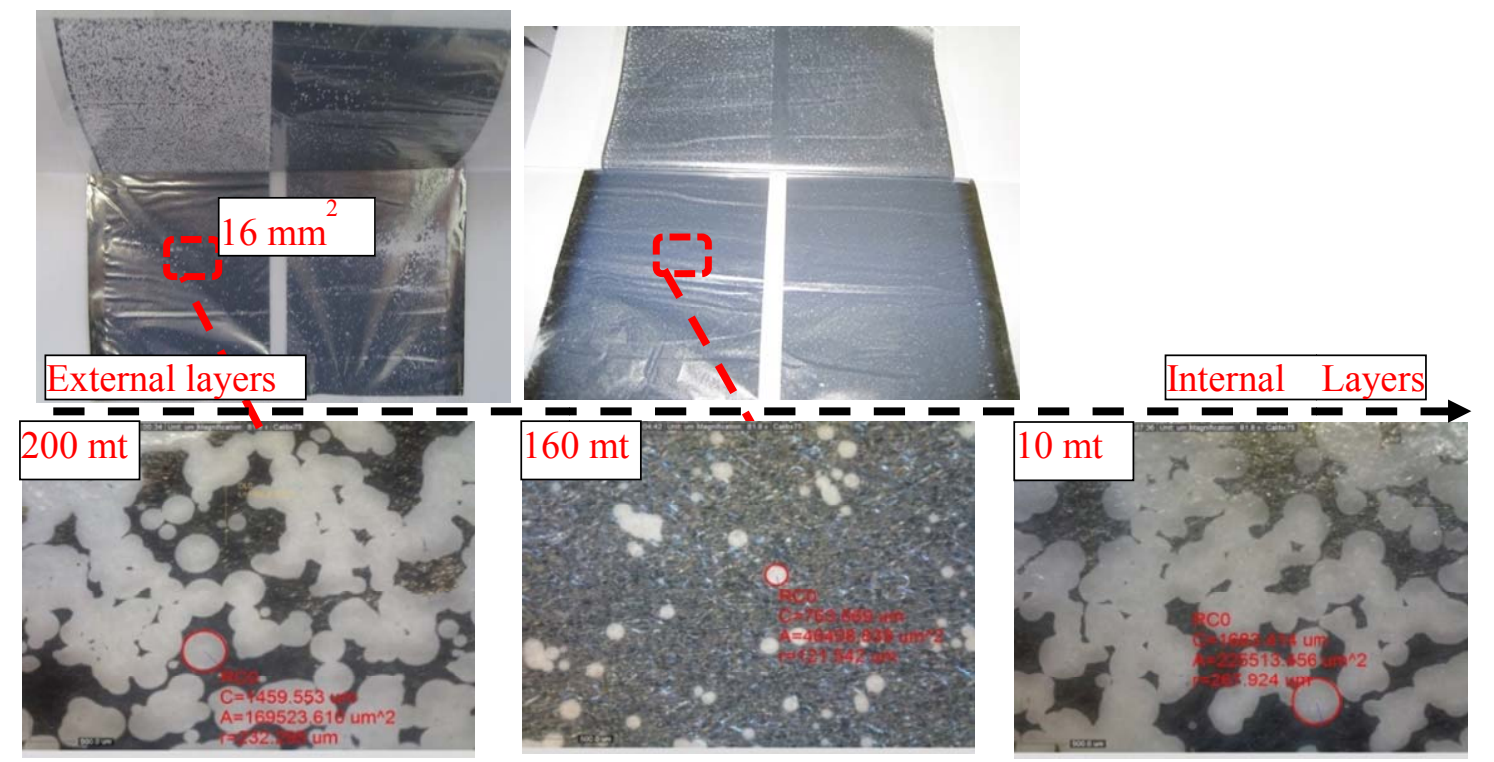

Figure 17: Solution N4 film condition after test1 (210 $\mathrm{mt}$ is the total length before starting to unroll)

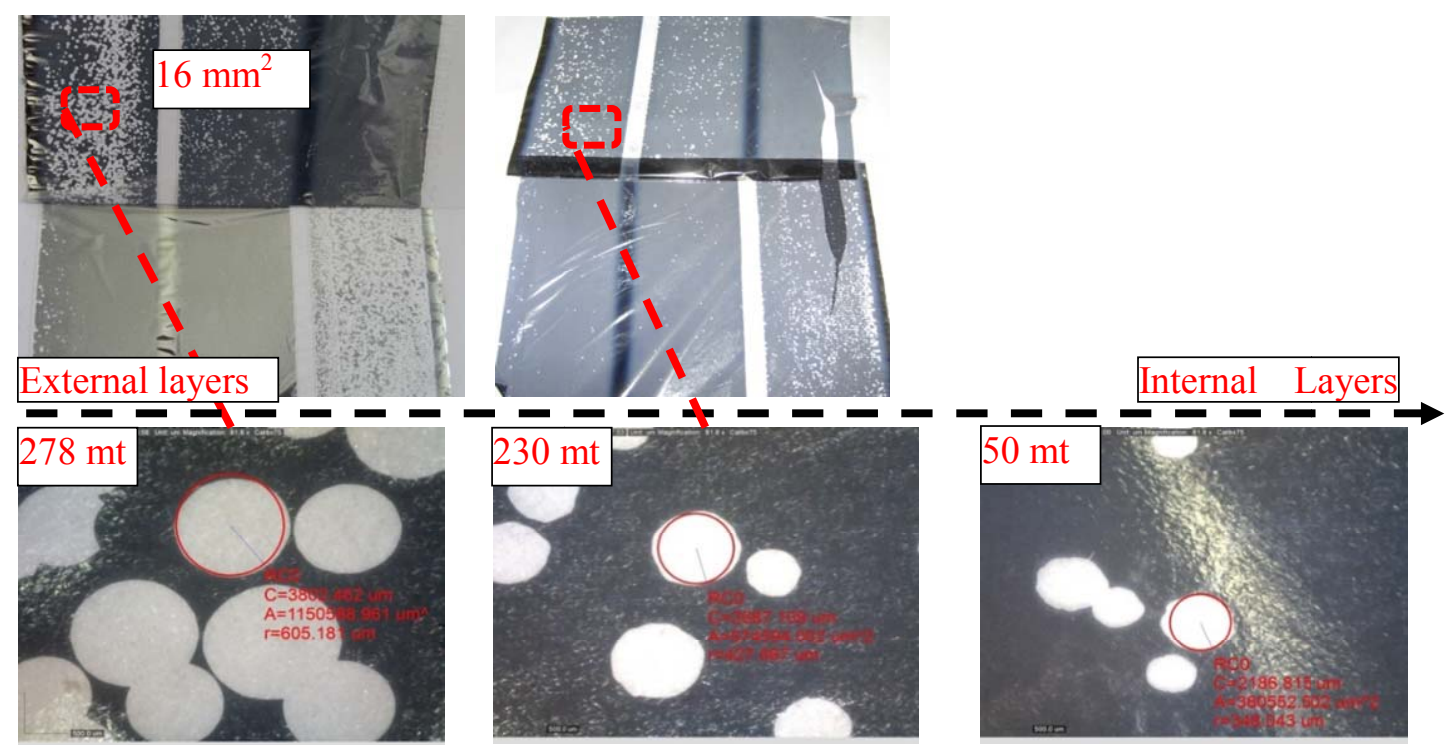

Figure 18: Solution N3 film condition after test1 (280 mt is the total length before starting to unroll)

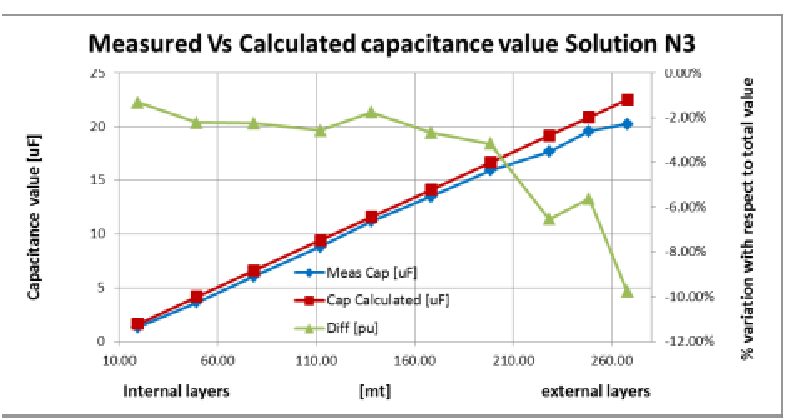

Solution N3 and N6 have the same design electric field and it is interesting to observe that in the three tests they had similar behavior (at least up to a capacitance loss of $5 \%$ ) although completely differently designed. The film inspection of Solution N3 (Figure 18 and Figure 19) reveals the same ageing type than the others.

Figure 19: Measured Vs Calculated capacitance for Solution N3 single roll.

\section{Conclusions}

The main factor affecting lifetime of HV capacitors for applications like the one described in this paper, seems to be corrosion of the metallization. This process is explained in [2] and [7] as the 
transformation of $\mathrm{Al}$ into circular islands of aluminum oxide $\mathrm{Al}_{2} \mathrm{O}_{3}$ (alumina). This would involve the migration of moisture from within the polypropylene to the polymer-aluminum interface where oxredox reactions would occur with the help of ac voltage, leaving $\mathrm{Al}_{2} \mathrm{O}_{3}$ circular islands on the metallization. Ref [7] also explains that the process seems un-affected by DC voltages; this consideration agrees with the fact that the Test1 and Test 2 didn't produce very different results in Solution N3, N4, N5 and N6 (Figure 20) for which metallization corrosion seems to be the most important ageing effect.
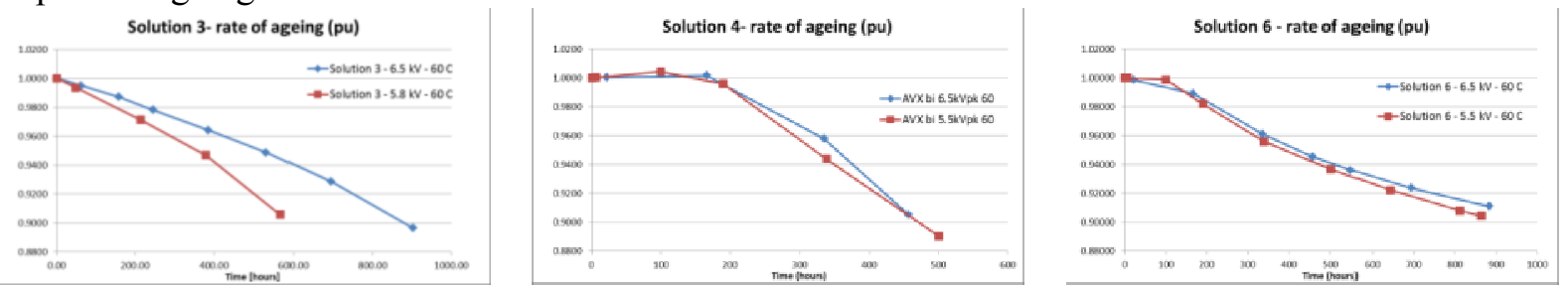

Figure 20: Ageing tests with different DC peak voltage values.

Ref [7] continues to explain that the growth rate of these little oxidation island is affected by the amount of $\mathrm{AC}$ voltage, therefore one of the factors that can be used to slow down the process is the reduction of the $\mathrm{AC}$ electric field stress i.e. the increase in the capacitor dimensions. On the other hand it is proved that the addition of $\mathrm{Zn}$ in combination with $\mathrm{Al}$ for the metallization is of great help to reduce the phenomena. When the same design used for Solution N5 was modified to have $\mathrm{Zn}+\mathrm{Al}$ metallization the results were completely different as shown in Figure 21.

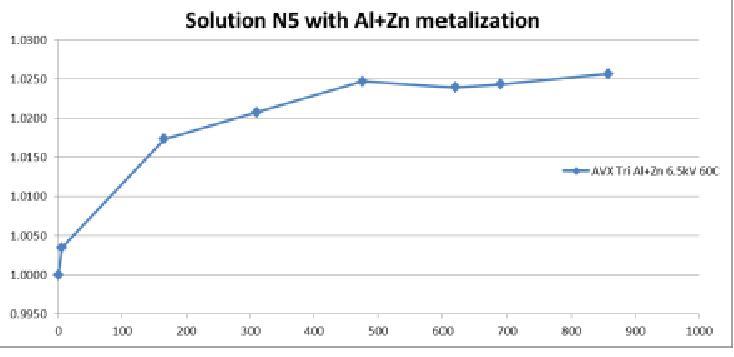

Figure 21: Ageing test1 results for Solution N5 with $\mathrm{Al}+\mathrm{Zn}$ metallization.

Another process causing electrode erosion is partial discharge occurring close to the edges and isolating the internal of the metallization from the electrodes. This effect seems to be more evident in the external layers of the capacitor basic unit as a consequence of the lower inter-layer pressure applied.

Additional tests are necessary to fully understand the stress limits of the analyzed solutions and to derive lifetime estimation based on Equation (4), but it appears from the preliminary results, that electrode corrosion would require electric stress reduction and/or mixed $\mathrm{Al}+\mathrm{Zn}$ metallization for oilimpregnated technology.

\section{Acknowledgements}

We would like to thank Mr Andre Marques Gomes and Mr Denis Durey for their help in running the tests and performing the teardown analysis.

\section{REFERENCES}

[1] M. Rabuffi, G. Picci "Status Quo and Future Prospects for Metallized Polypropylene Energy Storage Capacitors",IEEE transaction on plasma science, vol. 30 no. 5 October 2012.

[2] C.W.Reed, S.W. Cichanowski, "The fundamentals of aging in HV polymer film capacitors" IEEE transaction on Dielectrics and Electrical Insulation, Vol. 1 No. 5, October 1994

[3] A. Schneuwly, P. Groning, L. Schlapbach, , "Breakdown Behavior of Oil-impregnated polypropylene as dielectric in film capacitors" IEEE transaction on Dielectrics and Electrical Insulation, Vol. 5 No. 6, December 1998

[4] D. G.Shaw, S.W.Cichanowski, A.Yializis, "A changing capacitor technology- Failure mechanisms and design innovations", " IEEE transaction on Dielectrics and Electrical Insulation, Vol. EI-16 No. 5, October 1981

[5] W.B.Nelson, "Accelerated testing: statistical models, test plans, and data analysis" Wiley series in probability and statistics

[6] M.A. Kemp, C. Burkhart, T. Tang: "Lifetime Tests on a High Ohms/Square Metalized High Crystalline Polypropylene Film Capacitor with Application to a Marx Modulator"

[7] D.F.Taylor: "On the Mechanism of Aluminum Corrosion in Metallized Film AC capacitors" IEEE Transaction of Electrical Insulation Vol. EI-19 No 4 August 1984.

[8] I.Moumine, B.Gosse, J.P. Gosse, R.Clavreul, C. Hantouche : "Vegetable oil as an impregnant in HV AC capacitors" 1995 IEEE $5^{\text {th }}$ International Conference on Conduction and Breakdown in Solid Dielectrics.

[9] Emerson Network Power, Capacitors age and capacitors have an end of life, White Paper. 